\title{
LOS MINISTERIOS, ESPECIALMENTE LAICALES, EN UNA IGLESIA “MINISTERIO DE COMUNIÓN PARA LA MISIÓN"
}

DOI: https://doi.org/10.52039/seminarios.v53i185.582

Autor: Mons. Raúl Berzosa. Obispo auxiliar de Oviedo

Mons. Raúl Berzosa refresca nuestra memoria, al revisar la doctrina sobre el laicado, de manera minuciosa y clara. Señala también las últimas aportaciones desde el 2001 hasta la "Sacramentum Caritatis". Saca la conclusión de que hemos avanzado en este tema más por la fuerza de los hechos.

1.- Ministerios, carismas y funciones en una Iglesia "misterio de comunión para la misión"

Ya en el año 2001 fui invitado a escribir sobre el tema que nos ocupa ${ }^{1}$. Entonces, la Instrucción Vaticana emanada en 1997, y sobre la que volve-

${ }^{1}$ Cf. R. BERZOSA, Los ministerios confiados a los laicos: teología y praxis: "Seminarios" 159 (Enero-Marzo 2001) 35-50. Allí se señala la bibliografía fundamental sobre este tema: D. BOROBIO, Ministerios laicales, Atenas 1984; ID., Los ministerios en la comunidad, Editorial Litúrgica, Barcelona 1999; J. M. CASTILLO, Ministerios, en "Conceptos fundamentales de Pastoral", Cristiandad, Madrid 1983, 627 y ss; J. DELORME, El ministerio y los ministerios en el Nuevo Testamento, Cristiandad, Madrid 1975; S. DIANICH, Teología del ministerio ordenado, Paulinas, Madrid 1984; A. LEMAIRE, Les ministères aux origines de l'Eglise, Paris 1971; R. PARENT-S. DUFOUR, Los ministerios, Mensajero, Bilbao 1994; E. SCHILLEBEECKX, Los responsables en la comunidad cristiana, Cristiandad, Madrid 1983; B.SESBOUE, ¡No tengáis miedo!. Los ministerios en la Iglesia hoy, Sal Terrae, Santander 1998. 
remos, marcaba algo así como la brújula orientadora. ¿Desde entonces cuáles han sido los planteamientos más relevantes, al menos en el ámbito de lengua castellana?

Para encuadrar todo lo que se dirá a continuación hay que recordar el marco eclesiológico en el que nos movemos: misterio de comunión para la misión².

Que la Iglesia es misterio significa que es una realidad últimamente penetrada por la divina presencia, y por ello es de tal naturaleza que admite siempre nuevas y más profundas investigaciones. El misterio de la Iglesia no es un mero objeto de conocimiento teológico, sino un hecho vivido.

La Iglesia particular encarna sacramentalmente el misterio de la única Iglesia y ésta, a partir de su origen y ejemplar trinitario, se organiza en torno a la comunión y a la misión. Uno y otro elemento, en insoluble interacción, modelan trinitariamente a cada Iglesia y sustentan toda su eclesialidad.

La Iglesia es una realidad profunda y mística de comunión y misión al mismo tiempo (L.G. 1-13). Es la acción de Dios salvífica en el mundo que hace nuevas todas las cosas, creando fraternidad. Comunión y misión constituyen los dos aspectos fundamentales del misterio de la Iglesia. Se sostienen o caen juntos. Considerar sólo la comunión es arriesgarse al "ghetto", al grupo cerrado, a la secta. Quedarse sólo con la misión sería reducir la Iglesia a una empresa de acciones humanas y técnicas pastorales.

La Iglesia es misterio de comunión para la misión. En cuanto a la comunión, esa "unión común" no expresa tanto la unidad entre las Iglesias cuanto la unidad de la Iglesia en cuyo ser (el ser una y única) se identifican todas ellas. En esa conjugación entre "lo uno y lo múltiple" es donde se vislumbra el modelo mistérico trinitario. La Iglesia es fundamentalmente expresión de la comunión trinitaria, comunidad de fe, esperanza, caridad, y fraternidad vivida. Y, por lo mismo, corresponsabilidad. Traducido en otros términos: en la Iglesia todos los bautizados son necesarios; todos los bautizados deben ser miembros activos; los miembros de la Iglesia tienen diversos carismas y ministerios, y ejercen diversas funciones. Todo ello para edificar el cuerpo de Jesucristo y, sobre todo, para hacer presente a Jesucristo hoy entre nosotros.

2 R. BERZOSA MARTINEZ, Para comprender y vivir la Iglesia Diocesana, Burgos 1998; R. BLAZQUEZ, La Iglesia del Concilio Vaticano II, Sígueme, Salamanca 1988: M. KEHL, La Iglesia, Sígueme, Salamanca 1996; B. FORTE, La Iglesia de la trinidad, Secretariado Trinitario, Salamanca 1996. 
La comunión en la Iglesia tiene dos versiones: con el Dios Trino y con los hombres. La forma concreta de comunión de la Iglesia se manifiesta de esta manera: "Communio fidelium", por la que todos los fieles, como miembros del Pueblo de Dios, participan de la vida de la Iglesia y son corresponsables en la única misión y consortes en su destino; "Communio ecclesiarum", en cuanto la única Iglesia vive y se manifiesta en las Iglesias particulares; "Communio hierarchica", que manifiesta la apostolicidad de la Iglesia. Existe también otra dimensión de comunión, desde la santidad, la "Communio sanctorum", que se encuentra implícita en las otras dimensiones.

La comunión de la Iglesia es "abierta" a toda la humanidad, a un verdadero ecumenismo y a la Jerusalén celeste. Es "signo e instrumento de la unión íntima con Dios y de la unidad de todo el género humano" (LG).

La comunión con Dios Trino significa comunión con Dios Padre, Por Jesucristo, en el Espíritu Santo.

La comunión con el Padre es respuesta a la llamada que convoca a los "santos" (kletoi hagioi) a vivir su misma vida (Rom 1,7) en el seno de la asamblea de los llamados (koinonia Ekklésia). Comunión por el Hijo, para ser miembros de su cuerpo (LG 50; GS 32) cuya expresión máxima es la Eucaristía, misterio Pascual de Jesucristo (LG 7; AG 39; PC 15). Comunión en el Espíritu Santo. Él es quien guía a la comunidad de los santos y convocados por el Padre, confirmados en el Hijo, hacia la plena comunión y unidad (Gal 5,16-18; 1 Cor 12,4-11; 2 Cor 13,13). El Espíritu Santo, que vive en los creyentes y en la Iglesia, realiza aquella maravillosa comunión de los fieles y une tan íntimamente a todos en Cristo que es el principio de unidad en la Iglesia (UR 2). El Espíritu Santo es para la Iglesia y para todos y cada uno de los creyentes, principio de asociación (congregatio) y de unidad en la doctrina de los apóstoles y en la comunión, en la fracción del pan y en la oración (LG 13). El Espíritu Santo unifica, sin uniformidades, y regala diversos dones jerárquicos y carismáticos (AG 4; LG 4).

Pero el misterio de la comunión no es sólo con Dios Trino, sino también con los hermanos. Porque la comunión se hace fraternidad desde la participación en la vida teologal de Dios, sabiendo que esa fraternidad es al mismo tiempo don y tarea. Esta comunión con los hombres ofrece, al menos, estas características: comunitariedad, pluriformidad en la unidad, libertad de los hijos de Dios, reciprocidad, participación y corresponsabilidad mutua. Rasgos o notas todas ellas que hacen posible la experiencia sinodal y articulan y se expresan en dicha experiencia. 
La Iglesia, además de comunión, es también misión. La misión es una proyección de la comunión. Se ejercita desde, en y para la comunión. Es una misión comunional. Una misión que tiene su origen en el proyecto trinitario de la historia de la salvación, desde la creación a la elección del pueblo, hasta la misión de Jesús y la conciencia misionera de la iglesia apostólica. La misión, pues, encierra un significado trinitario y teologal. Nace de la caridad del Padre (RM 5), actualiza en cada momento de la historia la misión de Jesús, el Hijo de Dios (LG 13; AG 5; RM 20 y 24), y se hace posible por el Espíritu Santo (RM 21-30).

La misión es, además de don, una tarea histórica, contextuada, como diakonía de la caridad y diálogo interreligioso e intercultural. Las mediaciones de la misión son el anuncio (que incluye el kerigma, la doxología y la confesión de fe), unido al compromiso transformador y al testimonio martirial. Los destinatarios son todos los hombres y todo hombre. El fin último, la glorificación y el culto a Dios, haciendo que Él sea todo en todos. En otras palabras, hacer realidad el señorío de Cristo (su reinado).

Insistimos en la realidad de misión para la nueva evangelización. Esta dimensión se desgrana en diversos aspectos:

- evangelizar en cuanto tal (anuncio de la Buena Noticia),

- catequizar (profundizar en lo anunciado),

- celebrar la fe,

- vivirla y expresarla mediante el ejercicio de la caridad y el compromiso social personal y comunitario.

Cuando la misión se dice "Ad gentes" quiere significarse, con ello, la misión hacia pueblos y personas donde no se ha anunciado aún el cristianismo. En este sentido son como terreno virgen para el anuncio del kerigma.

Pero, además de ser "misterio de comunión para la misión", a la Iglesia se la puede denominar "ministerial y carismática".

\section{2.- Profundizando en el tema de los ministerios desde la sana Tradi- ción eclesial}

La Iglesia, misterio de comunión para la misión, puede ser definida también como "ministerial", tal y como se deduce de las cartas paulinas (1Tes 5,12; Rm 12,6-8; 1 Cor 12,4-11. 28-31; 14,6). Se puede leer en la primera Carta a los Corintios (1 Cor 12,12 y ss) que todos formamos un único cuerpo en Cristo. Todos nos necesitamos y debemos poner al servi- 
cio complementario de los demás los dones, funciones, carismas y ministerios que el Señor, el Espíritu y la misma Iglesia ha suscitado y sigue suscitando. San Pablo destaca al menos estos ministerios: el ministerio de apóstol, de profeta y de doctor (1 Cor 12,28; Ef 4,11). Sin olvidar los responsables de las comunidades, a quienes Pablo llama "sus colaboradores" ( $\operatorname{Rm} 16,3 ; 1$ Tes 3,2; 2 Cor 8,23; 1 Tes 5,12; 1 Cor 16,16), así como los evangelistas y pastores (Ef 4,1-6).

Podemos concluir que, desde el inicio, la Iglesia es carismática y ministerial; los ministerios hacen a la comunidad y la comunidad (con especial protagonismo de sus responsables) discierne esos mismos ministerios que otorga el Espíritu. La evolución histórica de los ministerios es muy compleja. En lo que afecta a los ministerios, se ha llegado a la conclusión de que existen ministerios:

a) por designación expresa de Jesús: los doce-apóstoles: Lc 6,13; Mt 10,2 ; Mc 6,30;

b) otros por designación del Espíritu Santo: ministerios señalados en las cartas paulinas (Rm 12,6-8; 1 Cor 12,8-11; 1 Cor 12,28; Ef 4,11);

c) y, otros, por designación de la Iglesia como, p. e., los "colaboradores" de los que se habla en Ac 6,1-6; 13,1-3 ó en las cartas paulinas (1 Cor 16,16; 1 Tes 5,12; Rm 16,1, etc).

Si el ministerio apostólico enlaza con el ministerio histórico de Jesucristo, ello no debe ir en perjuicio de los otros carismas y ministerios que existen en la comunidad. El ministerio ordenado garantiza la continuidad apostólica y sirve a la unidad de los diversos carismas y ministerios, pero no debe ser ejercido como opresión o anulación del resto de los carismas, vocaciones y ministerios existentes en la comunidad.

En el Concilio Vaticano II se redescubre que el conjunto de carismas y ministerios, ordenados y laicales, hacen posible la realidad de una Iglesia Trinitaria como "Pueblo de Dios", "Cuerpo de Cristo" y "Templo del Espíritu".

$\mathrm{Y}$, dentro de los ministerios, se han puesto de relieve precisamente los ministerios laicales.

A la hora de hablar de una teología renovada de los ministerios en la Iglesia, los teólogos insisten en el redescubrimiento de la identidad de los laicos y de su misión en la Iglesia y en el mundo. Se debe añadir el redescubrimiento del bautismo en lo que comporta de misión para todos los fieles y, finalmente, la participación de los laicos en el ministerio pastoral. No es algo totalmente nuevo. 
En la carta apostólica "Ministeria quaedam" (1972), Pablo VI escribió el primer texto oficial en el que se habla de los ministerios de los laicos cuando afirma que los ministerios pueden confiarse a los laicos de tal forma que no sigan estando reservados a los candidatos al sacramento del Orden.

El mismo Pablo VI, en "Evangelii Nuntiandi" (8-12-75), señalaba (n.70) que los seglares, en primer lugar, tienen como vocación específica la evangelización en medio del corazón del mundo en todos los ámbitos y ambientes. También añadía (n. 73), que los laicos pueden ser llamados a colaborar con los pastores para el servicio de la comunidad eclesial, ejerciendo ministerios y funciones muy diversos. Tales ministerios y funciones "son preciosos para la implantación, vida y crecimiento de la Iglesia". La Iglesia particular debe fomentarlos, formarlos y saber discernir su oportunidad y necesidad.

El Nuevo Catecismo de la Iglesia (1994), al hablar de los fieles cristianos (nn. 871-873) reconoce que entre los bautizados se da una verdadera igualdad en cuanto a la dignidad y acción, pero existen diversos ministerios, carismas y dones. Algunos, incluso, pueden ser llamados a colaborar con los pastores (n. 910). Todo para la común edificación del único cuerpo de Cristo.

En el Nuevo Catecismo se habla también de la participación de los laicos en la función profética de la Iglesia (nn. 785; 904-907; 942), en la función regia (nn. 908-913; 943), y en la función sacerdotal (nn. 901-903; 941).

Esta doctrina magisterial se verá ampliada y enriquecida en "Christifideles Laici" (1988).

Se nos recuerda que el fiel laico vive la comunión o inserción en la Iglesia desde la diversidad de carismas, ministerios, encargos y servicios. Se recuerda con ello el "sinergismo paulino" o la mutua edificación eclesial con la diversidad de dones que suscita y regala el Espíritu Santo). La Iglesia es comunión orgánica, que sabe conjugar la diversidad y la complementariedad. Lo distintivo no es la mayor o menor dignidad, sino el estar equipados y dotados para un mayor y mejor servicio. Todos los ministerios y carismas son dones para la participación y corresponsabilidad en la vida de la Iglesia. Hay ministerios que derivan del sacramento del Orden y sirven a la Iglesia personificando a Cristo Cabeza. Otros ministerios se pueden denominar como "laicales". Estos ministerios laicales no convierten a quienes los poseen o ejercen en "pastores", ni les "clericalizan". Estos ministerios, oficios y funciones se fundamentan en el 
bautismo y confirmación, y, para muchos, en el matrimonio (n. 22-23). Sin olvidar la participación de los laicos en la "vida ordinaria" de dicha iglesia particular.

Además de ministerios, el Espíritu otorga, para esta edificación de la Iglesia particular, carismas que deben ser acogidos con gratitud y sometidos al oportuno discernimiento.

A partir de "Christifideles Laici", y siguiendo la tradición, al hablar de funciones y ministerios laicales, podemos, en un primer momento, realizar la siguiente distinción:

a) ministerios laicales ocasionales, ejercidos en circunstancias determinadas y puntuales: voluntariado de caridad, catequistas, etc;

b) ministerios estables no sacramentales o instituidos: los principales, hoy, son lector y acólito;

c) ministerios sacramentales y públicos: tienen como base el sacramento del orden.

Estos ministerios denominados "laicales", tanto los ocasionales como los estables, desarrollarían las cuatro dimensiones tradicionales de la Iglesia particular, a saber: evangelización (martyria), caridad (diakonia), culto (leiturgia) y comunión (koinonia). Son ministerios importantes y necesarios y expresión del sacerdocio común bautismal de los fieles y de la riqueza de manifestaciones del Espíritu para la edificación de la Iglesia. A la hora de su reconocimiento, se oscila entre un "maximalismo" (pluralidad) y un "minimalismo" (monolitismo).

De esta tensión se hizo eco, ya en 1997, la Instrucción Vaticana "Sobre algunas cuestiones acerca de la colaboración de los fieles laicos en el sagrado ministerio de los sacerdotes". Recordamos los subrayados más importantes de la misma. Sobre ello volveremos. Antes, resumimos, en concreto, cuáles son dichos ministerios tal y como se deduce de una lectura del Código de Derecho Canónico (1983).

\section{Los ministerios laicales en el nuevo Código de Derecho Canónico ${ }^{3}$}

¿Cuáles son las novedades más sobresalientes del nuevo Código de Derecho Canónico? Al menos tres: el intentar una nueva fundamentación constitucional al hilo de la eclesiología del Vaticano II; el introducir un

${ }^{3}$ Cf. R. BERZOSA, Ser laicos en la Iglesia y en el mundo, DDB, Bilbao 2000, 71-77. 
nuevo criterio epistemológico en materia legislativa (ya no se trata de la razón filosófica y jurídica, sino de la fe y la teología); y la individualización de un nuevo protagonista en el ordenamiento jurídico: al clero le ha sustituido el fiel cristiano. La figura teológica y jurídica del fiel cristiano transciende y engloba la figura del laico, del clero o del religioso, e impide el erigir alguno de los tres estados como sujeto hegemónico del sistema legislativo.

La categoría de fiel (christifidelis) es la categoría fundamental del Código actual, en cuanto que el Bautismo es el fundamento. Todos los fieles sin distinción, en virtud de la consagración bautismal, son constituidos pueblo de Dios porque participan de la misma misión (munus) sacerdotal, profética y real de Cristo (c. 204,1). Este es el estado fundamental común a todos los bautizados que los distingue de los que no lo son. Hay, pues, una vocación común a todos, que es la de cooperar en la edificación de la Iglesia y la de actuar la misión que tiene que cumplir por mandato de Cristo en el mundo. Cada uno la cumple según sus funciones y su propia condición jurídica.

Supuesto lo anterior se puede afirmar, en síntesis:

- El Código ha valorado plenamente la posición eclesial del laico en la Iglesia siguiendo el esquema eclesiológico del Vaticano II, pero desarrollándolo desde una perspectiva del "fiel cristiano". Mientras que en 1917 aparecía el laico después de los religiosos y sacerdotes, al final del libro II, casi como un apéndice, ahora aparece en primer lugar, dentro del esquema del Pueblo de Dios (Libro II) inmediatamente después de los cánones sobre el fiel cristiano. En el Vaticano II, primero se colocó la jerarquía.

- Como queriendo hacer referencia al modelo constitucional civil se ha querido señalar un catálogo específico de derechos y deberes de los laicos apoyados en la doctrina conciliar del Vaticano II (cc. 224-231).

- En cuanto a "derechos y deberes seculares", se señalan: trabajar en la transformación de la realidad y gozar de la necesaria libertad (c. 225227); derecho de asociarse para lograr lo anterior (c. 327-329); derecho y deber de la familia en el sector de la educación de los hijos (cc. 226; 793; 796-799).

- En cuanto a los derechos y deberes radicados en la participación sacramental en los tres oficios de Cristo se señalan: enseñar, santificar y gobernar (LG 31,1). Aquí hay una doble distinción: los derivados del Bau- 
tismo y Confirmación, y los derivados de un oficio o ministerios que tradicionalmente se atribuían a los ministerios sagrados.

En el munus docendi se especifican: el anuncio del evangelio con la palabra y el ejemplo (c. 759,1); la catequesis en general (c. 225; 774; 776; $785 ; 528$; ), la catequesis matrimonial (c. 1063) y familiar (c. 774,2; 851); la evangelización como misionero (c. 784).

En el munus santificandi se concretan: la participación en los sacramentos (835-899) y en los ministerios litúrgicos dentro y fuera de la Eucaristía (c. 230). Así, ministerio extraordinario de la Palabra; acolitado y lectorado estables o temporales; ministerio extraordinario del Bautismo (861), de la comunión (c. 910), de la exposición del Santísimo (c. 943) y de la celebración de ciertos sacramentales (c. 1168).

En el munus regendi se expresan: las funciones de carácter consultivo (nombramiento de obispos y párrocos) (cc. 377,3; 524); participación en concilios particulares y sínodos diocesanos (cc. 443; 463) y en los consejos pastorales (diocesanos y parroquiales) $(512,519,536)$. Funciones de dirigentes o técnicos: moderador en asociaciones laicas públicas (c. 317,3); administración de bienes eclesiásticos (c. 956; c. 1282); oficios en los tribunales: asesor (c. 1424), auditor (c. 1428), promotor de justicia y defensor del vínculo (c. 1435), notario (c. 1436, c.438), procurador y abogado (c. 1482), perito (c. 1574), ayudante en los interrogatorios (c. 1528 y c. 1717), peritos en los procesos administrativos (c.1718), mediador (c. 1733), encargado de encontrar solución en las controversias administrativas (c. 1733); delegado y observador de la Santa Sede en Congresos Internacionales (c. 363).

Se señalan además algunos Oficios especiales: predicar en una iglesia u oratorio (c. 766); juez eclesiástico (c. 1421 y c. 1426); superior general de los Institutos de Vida Consagrada y de Sociedades de Vida Apostólica laical. En estos tres oficios especiales colaboran en el ejercicio de la Palabra o del poder de jurisdicción jerárquico. Colaborar no significa participar en la naturaleza de un poder $u$ oficio, como es el caso de los ministros ordenados.

Expuesto lo anterior, se hacen las siguientes observaciones:

- La doctrina canónica sobre los laicos se ha enmarcado perfectamente en una eclesiología conciliar, pero es muy genérica. El documento de 1997, como veremos en el apartado siguiente, afinará aún más;

- el munus de gobernar es contemplado sólo como "cooperación en el ejercicio del poder ministerial", es decir, en términos de suplencia (c. 
129,2). Y ello porque falta un libro sobre el oficio de gobierno y, con ello, el resaltar más el sacerdocio común, que en el actual Código sigue pareciendo integrarse en el sacerdocio ministerial. En este sentido, el Código diferencia:

a) Potestad de régimen en una Iglesia que es "sociedad visible", y que se puede participar por el sacramento del Bautismo (p. e.: un laico como juez diocesano (c. 1421) o administrador de bienes (c. 494) o que gestiona el Patrimonio o las funciones auxiliares en curias y tribunales;

b) potestad sagrada, esencialmente vinculada al sacramento del orden.

Ahora sí, dejando el Código, tendremos que adentrarnos en el Sínodo de 1987, con especial detenimiento en la exhortación postsinodal "Christifideles Laici”.

\section{4.- A vueltas con la Instrucción Vaticana del año 19974}

Como no podía ser menos, se reconoce a todos los fieles la colaboración en la misión de la Iglesia, tanto en el orden espiritual a la hora de llevar el mensaje de Cristo y su gracia a todos los hombres, como en el orden temporal, a la hora influir y perfeccionar el orden de las realidades temporales (p. 6). Por ello, como recordaba ChL (n. 23), los pastores son invitados a reconocer y promover los ministerios, oficios y funciones de los fieles laicos que tienen su fundamento sacramental en el Bautismo y Confirmación y, para muchos, en el Matrimonio. En orden a la nueva evangelización, se exige un equilibrio entre "el especial protagonismo" de los sacerdotes y, al mismo tiempo, la total recuperación de la conciencia de lo que supone "la índole secular" en la misión del fiel laico (Chl, $\left.\mathrm{n}^{\mathrm{o}} 15\right)$.

En cualquier caso se subraya constantemente que no se puede confundir el campo de los clérigos y el de los fieles laicos. Colaborar con el sagrado ministerio no significa "suplir ni sustituir" (p. 7). Se agradece especialmente la colaboración de los fieles laicos en tiempos de persecución, de missio ad gentes o de escasez de clero (p. 8). Para evitar irregularidades, matiza algunos principios teológicos:

1.- La diferencia entre sacerdocio común y sacerdocio ministerial no se encuentra en el sacerdocio de Cristo (el cual permanece siempre único

\footnotetext{
${ }^{4}$ Seguimos la edición en castellano de la Librería Editrice Vaticana (Ciudad del Vaticano 1997) 37 págs.
} 
e indivisible) ni tampoco en la santidad (a la cual están llamados todos los fieles) sino en el "modo esencial" de participación en el mismo y único sacerdocio de Cristo. Así, mientras el sacerdocio común de los fieles se realiza en el desarrollo de la gracia bautismal (vida de fe, esperanza y caridad), el sacerdocio ministerial está al servicio del sacerdocio común y se le ha conferido un poder sagrado para el servicio de los fieles. Para clarificar aún más los dos sacerdocios, la Instrucción nos recuerda algunas características del ministerio ordenado, apoyándose en "Pastores Dabo Vobis":

- El sacerdocio ministerial, obispos y presbíteros, hunde su raíz en la sucesión apostólica y está dotado de una potestad sacra, la cual consiste en la facultad y responsabilidad de obrar en persona de Cristo Cabeza y Pastor (PDV, $\left.\mathrm{n}^{\circ} 15\right)$.

- Son servidores de Cristo y de la Iglesia por la proclamación autorizada de la Palabra de Dios, de la celebración de los sacramentos y de la guía pastoral de los fieles (p. 11) (Cf. PDV, $\mathrm{n}^{\circ} 16$ ).

- Todas sus funciones (enseñar, celebrar, regir) forman una unidad. Por lo tanto, el ejercicio, por parte de los laicos, de alguna de estas funciones no les convierte en "pastores, sino en colaboradores" (p. 13).

- El ministerio ordenado es necesario para la existencia misma de la Iglesia. "No se debe pensar en el sacerdocio ordenado como si fuera posterior a la comunidad eclesial o como si ésta pudiera concebirse como constituida sin este sacerdocio" (p. 14) (Cf.ChL, no 16). El sacerdocio ministerial es, por tanto, insustituible.

2.- A partir de los anteriores principios teológicos, la Instrucción señala diversas disposiciones de carácter práctico. Destacamos las siguientes:

a) Necesidad de una terminología apropiada (pp. 17-18):

- Reservar, en principio, la palabra "ministerio" para el ministro ordenado; a los laicos, les corresponden "funciones".

- Una cosa es ser "ministro extraordinario" (cuando se es llamado por la autoridad competente para cumplir una función prolongada) y otra ser denominado, según la función ("catequistas, acólito, lector", etc). Nunca es legitimo a un fiel laico, designarle con apelativos como "pastor, capellán, coordinador, moderador", que se prestarían a confusión con lo que es un ministro ordenado. 
b) El fiel laico y el ministerio de la Palabra:

- a los laicos se les puede conceder "una suplencia" en casos de objetiva necesidad; pero no se puede convertir en un hecho ordinario ni puede entenderse como promoción del laicado (p. 20).

- La homilía, durante la celebración de la Eucaristía, está reservada al ministro ordenado. A los laicos, incluidos seminaristas, se les puede permitir una breve monición para entender mejor la liturgia que se celebra, o un testimonio en eventos especiales, o la posibilidad de intervenir en un diálogo dentro de la homilía. Fuera de la Misa puede ser pronunciada, por fieles no ordenados, según lo legislado (p. 21-22).

c) Ejercicio de párroco por parte de un fiel laico:

- Según el c. 517,2, puede ejercerlo por escasez de sacerdotes y no por razones de comodidad o de una equivocada promoción del laicado;

- siempre, se debe ejercer en atención al "ejercicio de la cura pastoral" y no para dirigir, coordinar, moderar o gobernar, que compete propiamente al sacerdote;

- se debe otorgar prioridad a los diáconos y agotar incluso la vía de los sacerdotes mayores (pp. 22-24).

d) Participación de los laicos en organismos de colaboración en la Iglesia particular:

- En el Consejo Presbiteral, sólo participarán sacerdotes en activo y en comunión con el obispo. Ni fieles laicos ni diáconos.

- En el consejo pastoral y económico, diocesano y parroquial, los fieles laicos participan como "consultores", al no ser organismos deliberativos. El consejo parroquial debe ser presidido por un párroco; son nulos los acuerdos en ausencia del párroco.

- Los grupos de expertos o de estudio no suplirán nunca a los consejos presbiteral y pastoral.

- Los arciprestes serán siempre presbíteros (pp. 24-26).

e) El fiel laico y las celebraciones litúrgicas:

- a un fiel laico o a un diácono no le es permitido pronunciar las oraciones y cualquier parte reservada al presbítero. No se puede ejercer una especie de "cuasi presidencia", dejando al sacerdote "lo mínimo" para garantizar la validez de la Eucaristía. Tampoco los laicos pueden utilizar ornamentos reservados al sacerdote o al diácono (estola, casulla, dalmática) (pp. 26-27). 
- En cuanto a las celebraciones dominicales en ausencia de presbítero, se debe tener especial mandato del obispo y son, siempre, ocasionales. No se pueden utilizar elementos propios de la liturgia sacrificial (ejem. plegaria eucarística).

- El ministro extraordinario de la Sagrada Comunión, también fuera de la Eucaristía, lo es cuando la necesidad lo reclama. Se puede nombrar "ad actum" (para el momento) por el sacerdote que preside la Misa. Es siempre de suplencia y extraordinario. Estos ministros no deben hacer la comunión ellos mismos como si fueran concelebrantes; tampoco se deben asociar a las promesas de los sacerdotes del día de jueves santo (pp. 2829).

f) El fiel laico y las celebraciones sacramentales:

- no puede un fiel laico administrar la unción de enfermos, ni con óleo bendecido para la unción ni con óleo no bendecido. La unción guarda estrecha relación con el sacramento de la reconciliación y la digna recepción de la Eucaristía (pp. 30-31).

- La asistencia a los matrimonios, por parte de los fieles laicos, requiere tres notas: ausencia objetiva de sacerdotes; que el obispo obtenga el voto favorable de la Conferencia Episcopal; necesaria licencia de la Santa Sede. Excepto el caso extraordinario del c. 1112, ningún sacerdote puede delegar a un fiel laico para asistir a un matrimonio (p. 31).

- En cuanto al bautismo, la ausencia de presbítero o el impedimento del mismo, que justifican el que un fiel laico pueda bautizar, no pueden asimilarse a las circunstancias de excesivo trabajo del ministro, o a su no residencia en el territorio de la parroquia, o a su no disponibilidad para el día previsto por la familia (pp. 31-32).

- La animación de exequias sólo puede ser ejercida por un fiel laico por verdadera falta del ministro ordenado y observando siempre las normas litúrgicas (pp. 32).

La Instrucción concluye haciendo una llamada a la formación adecuada de los fieles laicos y su necesaria selección para los ministerios.

A raíz de la Instrucción se ha escrito que "no se puede dar la impresión de rivalidad entre laicos y presbíteros... Como si los laicos buscan su promoción personal y los presbíteros defendieran su coto reservado... No hay que juzgar el ejercicio de los ministerios a partir de algunas disfunciones evitables"s. 
Debemos saber mirar siempre el futuro con valentía, creatividad, confianza, imaginación, apertura y sano discernimiento. Hasta aquí lo más destacado de lo escrito hasta el año 2001. Seguimos avanzando y profundizando.

\section{5.- Últimas aportaciones sobre el tema de los ministerios laicales (desde 2001 hasta hoy).}

¿Cuáles son las principales y más importantes aportaciones sobre los ministerios laicales en la actualidad?

Comenzamos haciéndonos eco de un libro de J. Rigal6. Después de esbozar un breve e interesante recorrido histórico, se detiene en el Vaticano II para hablar del redescubrimiento de la función de los laicos desde tres dimensiones complementarias (pp. 130-131): su fundamentación bautismal, su presencia en el mundo y el reconocimiento de ministerios propiamente laicales. En este último apartado habla de ministerios como "cooperación habitual en el apostolado jerárquico" (siguiendo a LG 33) y de ministerios como "suplencia" de ministros ordenados (LG 35). Pero reconoce que en nuestros días la presión de los hechos ante las necesidades evidentes ha sido un factor de evolución y progreso mayor que el desarrollo propiamente teológico (p. 131). El Concilio no podía imaginar la amplitud y ensanchamiento de perspectivas que se han abierto. Por eso es preciso recordar la fundamentación teologica.

Se puede hablar entonces de estructura ministerial de toda la Iglesia, que es comunión y, en este sentido, se debe integrar la dimensión cristológica del ministerio con la pneumatológica (pp. 135-149), haciendo posible el crecimiento de la dimensión comunitaria o de sinodalidad, de colegialidad episcopal y la dimensión personal del ministerio petrino (pp. 149165).

Después de clarificar lo que es y supone el ministerio ordenado, se centra de nuevo en el tema de la misión y ministerio de los laicos atreviéndose a afirmar que "ninguno de los documentos oficiales intenta de verdad proponer una clara definición ni tampoco unos criterios que per-

5 B. SESBÜE, ¡No tengáis miedo! Los ministerios laicales en la Iglesia hoy, Sal Terrae, Santander 1998, 195-197.

6 J. RIGAL, Descubrir Los ministerios, Secretariado Trinitario, Salamanca 2001. 
mitan distinguir mejor lo que pertenece al orden de "las tareas eclesiales" cotidianas y de los ministerios propiamente hablando"... porque si bien es cierto que todo ministerio es un "servicio" no todo servicio es un "ministerio" (p. 221). Se llaman servicios a aquellas prestaciones voluntarias, puntuales, ocasionales que algunos cristianos aportan a la vida de la comunidad. Estas tareas pertenecen a la corresponsabilidad global de todos los bautizados, pero estos servicios no exigen un estatuto eclesial particular.

El autor habla de ministerios "reconocidos" (en cuanto uno no se da el ministerio sino que lo recibe), y que pueden adoptar diferentes formas: desde lo ministerios formalmente "instituidos", con una liturgia de investidura, hasta un reconocimiento por designación o simple aprobación. En cuanto a los formalmente instituidos son, en la actualidad, el de lector y el de acólito) ${ }^{7}$. Los demás ministerios reconocidos, que tienen su fundamento sacramental en el bautismo y la confirmación (y para muchos en el matrimonio), abarcan un campo de ejercicio muy amplio: van desde la animación de la comunidad eclesial hasta un compromiso cristiano en los grandes sectores de la vida social (familia, jóvenes, vida profesional y cultural, instituciones sociales y políticas, salud, medios de comunicación, acción caritativa, etc.). Tratan de animar una doble realidad: la comunidad y la vida social (pp. 222-223).

Pero, junto a los ministerios que son reconocidos, y con base sacramental, han aparecido los "ministerios delegados" estrechamente vinculados al ministerio del orden y que no eran casi imaginados por el Vaticano II, aunque sí se habló de ello en dos textos (LG 35,4; AA, 24). Se debate en la terminología si hablar de ministerio en "ausencia de" o en "espera de"... Y hasta ciertos teólogos plantean si debe o no considerarse a quien lo ejerce como laico o como ordenado. Aunque Juan Pablo II lo dejó claro: "El ejercicio de esta función no convierte al fiel laico en un pastor; porque en realidad lo que constituye el ministerio no es la actividad en sí misma sino la ordenación sacramental” (pp. 225-226).

Finalmente, el autor aborda el tema de los ministerios en clave ecuménica y desde otros puntos de la praxis pastoral que no nos detenemos en ellos y que son la parte más discutible del libro (pp. 233-264). En la

\footnotetext{
${ }^{7}$ Cabe la posibilidad, según el autor, de que sean conferidos también a mujeres: Cf. La Nota de la Sagrada Congregación para Los Sacramentos y el Culto Divino, Novit Profecto (27-101977).
} 
conclusión se hace una llamada a ser creativos desde la fidelidad y a redescubrir al mismo tiempo la Iglesia y los ministerios, según las necesidades actuales (pp. 265-267).

También en el año 2001 aparece un libro de Joaquín Perea ${ }^{8}$ sobre el laicado. Pretende ser como un manual. Afronta el tema del ministerio laical. En un primer momento, en su relacionalidad y complementariedad con el ministerio ordenado (pp. 355-379), especialmente en dimensiones como el testimonio de la fraternidad de Cristo, promotores de la justicia liberadora de Cristo, anunciadores del reino mesiánico de Cristo. Aunque advierte que los conflictos entre laicos y presbíteros se dan principalmente por la excesiva "jerarquización eclesial" (los laicos parecen jugar en "Campo contrario"), por los "procesos de decisión" (se minusvalora al laico) y por la clarificación de la autonomía de los laicos (excesiva centralización eclesial) (pp. 376-377). Y, en lo referente a los ministerios propiamente laicales, una vez expuesta su fundamentación eclesial y pneumatológica, se centra en algunas consideraciones de carácter pastoral a tener en cuenta en el futuro, tales como (pp. 393-400):

- la estrecha relación entre ministerios laicales y pastoral de conjunto;

- la complementariedad entre presbíteros y laicos para no caer en clericalismos y en "laicalismos";

- mantener siempre en el horizonte la dimensión secular y la pluralidad de opciones en materia sociopolítica;

- y, finalmente, la resolución de la "presidencia" de los laicos a tenor del c. 517,2. Teología y necesidades contextuales deben caminar de la mano.

Sin salirnos del año 2001, D. Borobio publica una obra que culmina sus trabajos anteriores sobre ministerios laicales ${ }^{9}$. En su planteamiento, se unen ministerios y corresponsabilidad eclesial (pp. 19-28). La corresponsabilidad se entiende desde un ser "todos" Iglesia, participar en la misma misión, ser todos servidores de la comunión y participar de carismas. Los ministerios son precisamente mediaciones al servicio de la Palabra, de la liturgia y de la comunión.

8 J. PEREA, El laicado: un género de vida eclesial sin nombre, Desclée de Brouwer, Bilbao 2001.

${ }^{9}$ D. BOROBIO, Misión y ministerios laicales, Sígueme, Salamanca 2001. 
Los ministerios se fundamentan en los sacramentos. Así, el Bautismo es la fundamentación radical de todos los servicios y ministerios (pp. 6469); la Confirmación, supone la aceptación pública de la tarea ministerial (pp. 70-74); el Orden es la consagración para la animación de servicios y ministerios (pp. 75-78); el Matrimonio es el compromiso para un ministerio plural (pp. 78-81); la Penitencia, la renovación de la condición ministerial del cristiano (pp. 82-83); la Unción, la llamada ministerial en la situación de enfermedad (pp. 84-85); y la Eucaristía, el centro de vivificación ministerial (pp. 86-88). Es importante revalorizar a la mujer en el tema de los ministerios (pp. 89-120). A partir de los planteamientos anteriores, con originalidad, D. Borobio quiere subrayar algunos ministerios:

a) El ministerio de catequista-guía del catecumenado con sus funciones iniciatoria, comunitaria, didascálica, vivencial, testimonial y mistagógica (pp. 121-160).

b) El ministerio de educador cristiano con su función humanizadora, inculturadora, evangelizadora, iniciadora, eclesial-comunitaria y familiar (pp. 161-188).

c) El ministerio del comunicador cristiano, con sus funciones informativa, comunicativa, formativa, evangelizadora y representativa (pp. 189214).

d) El ministerio de sanación, con sus funciones específicas de salud integral (pp. 215-260).

e) El ministerio de promotor de la pastoral familiar, con sus funciones hacia "dentro" y "hacia fuera" (pp. 261-300).

f) El ministerio de reconciliación y pacificación con su función laical de consejo y acompañamiento, de mediador de paz y reconciliación, de acogida y fraternidad (pp. 301-336).

g) El ministerio de animación litúrgica y de comunión (pp. 337-360).

Como conclusión, se pide el desarrollo armónico y en equilibrio de los diversos ministerios (ordenados y otros) y la atención del desarrollo ministerial en dos ámbitos diferentes: el rural y el urbano (pp. 361-365).

D. Borobio, finalmente, nos regala un decálogo para la promoción de servicios y ministerios (pp. 365-369):

1.- Tener clara la identidad de lo que son los ministerios.

2.- Analizar la realidad en donde se va a servir.

3.- Priorizar los servicios y ministerios más necesarios.

4.- Concretar los más inmediatos y urgentes. 
5.- Discernir los carismas personales.

6.- Ofrecer medios para la formación.

7.- Acompañamiento permanente.

8.- Favorecer una pequeña comunidad de fe y de misión.

9.- Distinguir entre "servicios" y "ministerios".

10.- Promover permanentemente nuevos servicios y ministerios.

En el 2003, aparece un libro muy interesante sobre la Situación de los laicos (identidad, misión y ministerios) en Europa. Lleva la firma de J. Martínez Gordo ${ }^{10}$.

En dicha obra se aportan datos globales para un análisis de la Iglesia en Europa (pp. 285-344). Sobresalen los siguientes: Aumento de parroquias sin sacerdote residente; descenso y envejecimiento del clero; descenso de la práctica sacramental; mentalidad laicista (ni siquiera se desea que aparezca el nombre en la Constitución Europea); hacia una Iglesia minoritaria en una sociedad crecientemente indiferente; el laicado se sitúa entre la corresponsabilidad y la sustitución; y la crisis eclesiológica manifestada en el ecumenismo y diálogo interreligioso, en cómo entender el primado, y cómo ejercer el ministerio ordenado.

El autor se centra también en la singularidad del caso español (pp.1390), donde sigue siendo mayoritario lo católico; donde se da una valoración positiva de los misioneros, de Cáritas, de la Pastoral Penitenciaria, y de Manos Unidas; donde el asociacionismo es rico y variado; donde se sigue dando importancia a la Enseñanza Religiosa Escolar; y donde se sigue manteniendo una cierta situación jurídica "protegida" por el Estado.

Se señalan tres objetivos básicos para las Iglesias europeas en estos momentos: Impulsar la pastoral vocacional general, y la presbiteral de forma particular; la reorganización territorial; y el promover la corresponsabilidad del laicado (P. e., Alemania se ha decantado por promover el laicado sin descuidar la reorganización territorial; Francia, la reorganización territorial, sin descuidar la promoción del laicado).

Para favorecer una pastoral vocacional renovada, se hace hincapié en recuperar la Fe; en equilibrar, en lo eclesiológico, lo cristológico (Cuerpo de Cristo), con lo pneumático (ministerios del Espíritu); y dar una mayor cabida a los ministerios laicales.

${ }^{10}$ Cf. J. MARTINEZ GORDO, Los laicos y el futuro de la Iglesia, PPC, Madrid 2003. 
En cuanto a la reorganización territorial, dos polos a tener en cuenta: lo territorial y la promoción de ministerios, servicios, funciones. Al mismo tiempo, dos puntos de mira: lo eclesiológico y lo sociológico. Y tres maneras de entenderlo y ponerlo en práctica:

a) confección de un nuevo mapa pastoral que permita una visión global de toda la Iglesia local. Se va de lo global a lo singular.

b) Agrupación de parroquias vecinas y semejantes, tanto por razones pastorales como sociales, para, partiendo de la atención preferente a estas agrupaciones singulares, ir elaborando un nuevo mapa pastoral de la diócesis. La visión de globalidad es el resultado final de un proceso orientado, obviamente, por unos criterios mínimos y consensuados.

c) El obispo diocesano nombra un equipo de presbíteros para una determinada zona o agrupación de parroquias -contando siempre que se pueda con el consentimiento de la gran mayoría de sacerdotes- y les encomienda trabajar conjuntamente y proceder a la agrupación de las diferentes realidades pastorales.

El primero es un modelo preferentemente más deductivo (en cuanto prima la globalidad) (ejem. Pamplona); el segundo, más inductivo (p. e., Oviedo); y el tercero más episcopal-ministerial (p. e., Bilbao).

¿Cuáles son las dificultades que se perciben a la hora de la reorganización territorial?:

- Una feligresía tradicional, de edad avanzada, que quiere que todo siga como hasta el presente.

- La afección a la propia parroquia, que impide compartir recursos materiales y humanos.

- El miedo a lo nuevo, a lo desconocido.

- Las parroquias mejor dotadas de recursos no sienten ninguna necesidad de participar en el nuevo proceso.

- La desconfianza en la voluntad real del consejo de gobierno diocesano.

Finalmente se habla de los laicos con encomienda pastoral. Se distingue una variada tipología:

1.- Encomiendas en régimen de voluntariado en el anuncio de palabra (catequistas), animación litúrgica, promoción de la caridad.

Lo más positivo: crece la conciencia de corresponsabilidad. Lo menos positivo: capacitación y formación, problemas de relación con los profesionales. 
2.- Docencia de religión con "missio canónica". Lo más positivo: buen trabajo y buena voluntad. Lo menos positivo: las reivindicaciones laborales pueden imponerse sobre lo vocacional.

3.- Celebraciones dominicales en ausencia de presbíteros. Lo más positivo: conciencia de corresponsabilidad y desarrollo de ministerios. Lo menos positivo: falta formación en los agentes y sensibilización en quienes los reciben; condena de comunidades a la no presencia regular del presbítero; tal vez no poner todo el acento en la pastoral vocacional al sacerdocio ministerial.

4.- Encomienda pastoral y con liberación económica (con proceso de discernimiento vocacional y compromiso de formación). Está muy en mantillas y en una Iglesia más bien "pobre".

En resumen, se ofrecen dos grandes modelos:

a) El alemán: laicos que han realizado un discernimiento vocacional, con alta formación teológica, trabajo como plena dedicación y entendido como carrera profesional, definidos los servicios pastorales y el estatuto de remuneración económica. Problemas más importantes de esta experiencia: dependencia del obispo, problemas de tipo laboral, dependencia del Estado en cuanto al tema económico (impuesto religioso), funcionarización y poca participación de la comunidad a la hora de elegir a quienes deben prestar un servicio pastoral.

b) El francés y suizo: lo anterior, en escala más "económica" y protección "menos jurídica", pero donde la comunidad juega un papel importante. Problemas más llamativos: amenaza de presidir la Eucaristía si no se resuelve el tema de la escasez presbiteral.

Un punto aparte es la fundamentación jurídica de los laicos con encomienda pastoral:

a) Para unos, es una forma de participación "delegada" en la cura pastoral y en las funciones episcopales como lo es el ejercicio pastoral del presbítero (J. Grange).

b) Para otros, son simples colaboradores del ministerio presbiteral (J. C. Perisset). No participarían de la cura pastoral sino que reciben un oficio para actuar como colaboradores estables y permanentes del presbítero moderador que es el verdadero "pastor".

c) Finalmente, otros lo entienden como una corresponsabilidad desde el carisma propio (A. Borras, A. Montan). Esto quiere decir que todos son titulares de la cura pastoral, pero en grados diferentes. Igualdad radi- 
cal de todos y diversa cooperación en la edificación del único Cuerpo de Cristo.

Como conclusión, se aboga por unir tres aspectos: la reorganización del territorio, potenciar equipos apostólicos, y proyecto de acción pastoral con los ministerios específicos.

La editorial Monte Carmelo inició hace unos pocos años la colección "Diccionarios Norte". El tema de los ministerios es abordado al menos en dos de ellos. El primero, en el año 2003, en el "Diccionario del agente de pastoral litúrgico". D. Borobio (pp. 386-387) resume el tema de los ministerios instituidos distinguiendo entre servicio y ministerio. Y nos ofrece las claves para que pueda darse un verdadero ministerio laical: que la persona esté capacitada (carisma) y cualificada (preparación o formación necesaria), que tenga experiencia en el ejercicio de la función (ejercicio pastoral); que sea aceptada por la comunidad cristiana a la que desea servir (ejemplo de vida); que acepte el compromiso con cierto grado de pertenencia (entre 3-5 años); que reciba la encomienda y sea enviado oficialmente por el obispo o su representante. Sólo con esas condiciones se puede hablar de ministerio para distinguirlo de servicio sin olvidar que todo ministerio es para servir.

Por su parte, R. Calvo (pp. 483-487), escribe la voz Ministerios en el "Diccionario del laicado y Movimientos y asociaciones laicales" (2004). Se recuerda cómo la Iglesia se articula desde lo carismático y lo ministerial. El desarrollo de los ministerios vendría por una triple dimensión:

1.- Valorar el bautismo y lo que supone de compromiso ministerial.

2.- Necesidades y estructuración eclesial para cumplir su misión.

3.- Necesidades de evangelización.

De la confluencia de los tres factores anteriores, se detectan cinco vías para el desarrollo de los ministerios:

a.- Servicios de dirección: responsabilidad o coordinación de áreas o sectores, consejos de pastoral y de economía, etc.

b.- Servicios para la celebración y la liturgia.

c.- Servicios de transmisión y profundización de la fe: teólogos, catequistas, etc.

d.- Servicios para el compromiso cristiano en lo social.

e.- Servicios para anunciar la buena nueva, tanto a los alejados como a los no creyentes. 
Recuerda, finalmente, R. Calvo que existen otras distinciones en el tema de los ministerios, como la clásica entre instituidos y reconocidos; o la de ministerios permanentes y esporádicos.

Precisamente R. Calvo vuelve a hablar del tema de los ministerios, en clave de futuro y creativa, dentro una interesante obra de pastoral publicada en el $2004{ }^{11}$. Lo que afecta a nuestro interés, aunque se fundamenta en todo lo que escribe anteriormente, se inserta en el apartado "Unos nuevos animadores pastorales" (p. 295-300).

Se subraya que todo el Pueblo de Dios es co-protagonista de la animación pastoral. El papel específico de los pastores no es colocado fuera de la comunidad ni frente a ella sino en constante correlación con todos los miembros eclesiales, llamados a una misión activa. Desde esta perspectiva, la acción pastoral se entiende como el carisma (don) que el Espíritu concede a su Iglesia toda, en y desde las católicas Iglesias locales para bien de su propia edificación al servicio del Reino. Pero es un carisma global que necesita de personas concretas y de sujetos colectivos en el entramado interpersonal de la comunión. Por todo ello se necesitan animadores de pastoral creativos que, lógicamente, llevarán a suscitar ministerios nuevos.

En la misma dinámica de abrir caminos nuevos para la identidad y misión de los laicos, encontramos el libro de C. García de Andoin ${ }^{12}$. En el capítulo IX se habla de impulsar la corresponsabilidad y la ministerialidad laical (pp. 291-330). Y se subraya la "precaria y sumergida realidad de los ministerios confiados a los laicos" (p. 304). Las cuestiones que se plantean son de diversa índole:

a.- Índole Pastoral: Si los laicos deben ejercer ministerios más hacia dentro (eclesiales) o hacia fuera (sociedad); si deben ser ejercidos desde la liberación para ello o desde el voluntariado; si los ministerios deben estar respaldados por el envío oficial o no; en el tema del discernimiento, qué papel corresponde a la persona y cuál a la comunidad; qué formación se necesita y cómo designar de forma adecuada los ministerios.

b.- Índole existencial y teologal, donde está en juego el concepto y la vivencia de Iglesia y la relación con el mundo. Así como la complementariedad entre ministerios ordenados y no ordenados.

${ }^{11}$ R. CALVO, Hacia una pastoral nueva en misión, Monte Carmelo, Burgos 2004. 
C. García de Andoin se atreve a plantear tres problemas muy concretos (pp. 316-325):

1.- Si los ministerios laicales derivan del bautismo o son una colaboración/participación en el ministerio ordenado.

2.- Si los ministerios laicales son solo extraordinarios o primicia de una nueva ministerialidad.

3.- Si se debe mantener la diferencia esencial y no de grado entre sacerdocio ministerial y sacerdocio común.

Finalmente se aboga por una nueva clarificación en el tema de los ministerios (pp. 325-330), promovido, como sucede en el caso francés, por la reordenación territorial. Porque no se puede olvidar que la Iglesia no es comprensible sin la ministerialidad pero los ministerios han tenido diferentes concreciones a lo largo de la historia. Los rasgos de los ministerios derivados de los sacramentos como los fundados en una estrecha asociación al ministerio sacerdotal ofrecen estos rasgos: ministerios abiertos tanto a hombres como mujeres; ministerios más temporales; ministerios más seculares; ministerios más poliformes y analógicos (con remuneración o no, estables y menos estables, casados y célibes, etc); mucha atención a la formación; $y$ una equilibrada relación entre ministerio laical y ministerio presbiteral y entre ministerios y comunidad.

Entre el 2005 y el 2006 han aparecido diversos diccionarios donde se tocan, de diversa manera, las voces sobre ministerio-ministerios. Así M. Guerra, al hablar sobre Ministerio y Ministerios ${ }^{13}$, recuerda que todos los bautizados participan del único sacerdocio de Cristo y que todos ejercen diversos ministerios, si bien se debe diferenciar entre sacerdocio ministerial y otros ministerios. Por su parte, J. Camarero se centra en el ministerio de la Palabra ${ }^{14}$. N. López Martínez, se encarga de la voz Ministerio en el "Diccionario de Teología"15. Distingue entre las diversas formas de servicio eclesial:

12 C. GARCIA DE ANDOIN, Laicos cristianos, Iglesia en el mundo, Ediciones HOAC, Madrid 2004.

13 Profesores de la Facultad de Teología de Burgos, Diccionario del Sacerdocio, BAC, Madrid 2005, 430-441.

14 Profesores de la Facultad de Teología de Burgos, Diccionario del Sacerdocio, BAC, Madrid 2005, 442-455.

15 AA.VV., Diccionario de Teología, EUNSA, Pamplona 2006, 640-644. 
Algunas (episcopado, presbiterado y diaconado) presuponen la recepción del sacramento el orden; otro (ministerio petrino) por la legítima elección canónica (c. 332); otros, por la institución mediante un sacramental (lector y acólito); y otros incumben a todos los cristianos por el hecho mismo de serlo. Entre todos los ministerios se da jerarquización e interdependencia. Finalmente, R. Gerardi16 vuelve a fundamentar los ministerios eclesiales en la dimensión cristológica y eclesiológica; distingue entre ministerios ordenados y ministerios laicales. Y éstos, los laicales, se dividen en instituidos y "ministerios de hecho", suscitados por el Espíritu y que ofrecen una gran variedad. En cualquier caso, los ministerios, siguiendo el documento de la Conferencia Episcopal Italiana "Evangelización y ministerios" (1977), ofrecen las siguientes características: origen sobrenatural (nacen del Espíritu Santo); fin y contenido eclesial; prestación estable no sólo temporal y transitorio; reconocimiento público en la comunidad. Se aporta una nota importante: los ministerios son para la comunión, son siempre "junturas y medios de comunión" porque provienen del único espíritu de Cristo que anima a la Iglesia. Y son para construir un único cuerpo. Y, para el futuro, se proponen las siguientes pautas:

1.- Promover los ministerios.

2.- El bautismo y la confirmación son los sacramentos básicos de donde dimanan los ministerios cristianos.

3.- Como no se encuentran en estado puro, hay que hacer que emerjan y que se tome conciencia de ellos.

4.- Que un ministerio produzca fruto no depende sólo del carisma recibido del Espíritu Santo o del reconocimiento de la Iglesia, sino también de la santidad del ministro, de la fe y caridad reales.

Entre la bibliografía más reciente, nos hacemos eco, por último, de un libro de J. Aldazábal ${ }^{17}$. El autor recuerda cómo es toda la comunidad la que celebra y los ministerios se otorgan al servicio de la comunidad. Los ministerios litúrgicos se dividen en ordenados, instituidos, reconocidos y "de hecho" (pp. 15-18). Los rasgos comunes de los buenos ministros serían: personas de buena fe; que participan en la liturgia; que entienden su ministerio como servicio; que existe coordinación entre ellos; distribuidos

16 AA.VV., Diccionario de Pastoral Vocacional, Sígueme, Salamanca 2005, 686-693.

17 J. ALDAZABAL, Ministerios al servicio de la comunidad celebrante, Centro de Pastoral Litúrgica, Barcelona 2006. 
en diversidad de personas y no cumulados en una persona; formación y preparación; y mejorando progresivamente en sus condiciones humanas (pp. 21-25). Dejamos los ministerios de Presidencia y de Diácono y nos centramos en los denominados ministerios confiados a los laicos. En principio, J. Aldazábal, diferencia ministerios en tres ámbitos (pp. 55-59):

1.- En el ámbito de la Palabra.

2.- En el ámbito de los servicios de la caridad.

3.- En la dirección de la comunidad

4.- En la celebración litúrgica: tanto en la preparación y celebración de los sacramentos en colaboración con el sacerdote, como en la celebración de la Eucaristía, y en la ausencia o espera del presbítero.

De todos estos ministerios, que incluye a la mujer, J.Aldazábal (pp. 69239) destaca de forma pormenorizada los siguientes: sacristán, servicio de acogida, monitor o comentarista, acólito, lector, director de canto, coro, salmista, organista, ministro de la comunión, equipo de liturgia, padrinos y celebrantes dominicales en ausencia del presbítero. Se concluye con una llamada de atención conocida: hay que promover los varios ministerios y recordar que los ministerios no son sólo litúrgicos (pp. 242-243).

Fruto de la XVII Semana de Teología Pastoral, el Instituto Superior de Pastoral de la Universidad Pontificia de Salamanca, publicó la obra Hablan los laicos (2007)18. En la parte segunda, en la sección de Coloquios, se planteó expresamente el tema "Ministerios laicales, ¿cuáles?". En una primera intervención, Javier del Barrio ${ }^{19}$, desde la Renovación Carismática Católica, habla de tres nuevos ministerios (pp. 186-187):

1.- Servicio para la liberación del malestar interior o consejero moral. Se refiere a la falta de sentido de la vida, a la falta de identidad personal, a la ausencia de valores, al vacío interior.

2.- Servicio de visita a enfermos, ministros de los enfermos. Serían hombres y mujeres dotados de carisma para sintonizar con la situación anímica de los enfermos, especialmente de los más graves. Se trata de una ayuda no sólo anímica sino de saber descubrir la presencia del Señor.

3.- Tutorías espirituales en el campo educativo. Se trata de una especial y personal atención a los alumnos y de su orientación existencial.

18 INSTITUTO SUPERIOR DE PASTORAL, Hablan los laicos, Verbo Divino, Estella 2007.

19 Servicios laicales en una parroquia, 179-188. 
Entre los más nuevos ministerios laicales, añadimos además, por su originalidad y funcionalidad, otros tres: el denominado animador de grupos, el coordinador pastoral, y el animador de la cultura.

El animador de grupos ha tomado cuerpo y se ha visto consolidado dentro de la nueva Acción Católica, especialmente en el campo juvenil. Junto al Consiliario, son como dos pilares troncales para que los grupos crezcan y cumplan su misión ${ }^{20}$.

La figura y ministerio del coordinador pastoral se contempla como un verdadero y necesario servicio en favor de la comunidad parroquial en sus diversas dimensiones o ámbitos. Figura desarrollada especialmente en América Latina. Dicha figura no está llamada a trabajar en solitario, sino formando un verdadero equipo con otros cualificados agentes de pastoral21.

Más novedoso y llamativo resultará, sin duda, el ministerio del animador de la cultura, especialmente en la denominada "cibercultura". Los obispos italianos hablan de dicho ministerio 22 como complementariedad de quienes ejercen ministerios litúrgicos, catequéticos o de caridad. No suplanta los demás sino que potencia la creatividad y la imaginación a la hora de evangelizar en la nueva cultura emergente. Es fruto de una Iglesia que se sabe misionera y de puertas abiertas. Para entender la figura del animador de la cultura hay que explicar lo que significa la sala de la comunicación creativa: "Estas salas se han convertido en algo propedéutico al templo, punto de referencia y de interés también para los alejados, servicio al Pueblo de Dios, y también a todos los hijos de Dios dispersos" (Juan Pablo II). Hay que reservar en las obras parroquiales un ámbito para destinarlo a la sala de la comunicación y a los varios servicios que ésta puede prestar a la comunidad misma y a los alejados. Esta sala no se entiende sin más como la del cine-club clásico, sino como una verdadera y propia estructura pastoral al servicio de la comunicación creativa y evangelizadora y del encuentro con creyentes y alejados. Puede servir para la primera evangelización y para consolidar la comunidad. Basta disponer de un espacio equipado con algunos de los modernos instrumentos de la comunicación audiovisual. Algunos de los varios servicios que dicha

20 Cf. COMISION EPISCOPAL DE APOSTOLADO SEGLAR, La pastoral y la Acción Católica en la Iglesia Diocesana, EDICE, Madrid 2000; R.BERZOSA, Voz "Acción Católica" en "Diccionario de Pastoral y Evangelización", Monte Carmelo, Burgos 2000, 15-17.

21 Cf. J.L. GARCIA, El coordinador de Pastoral, PPC, Madrid 2007. 
Sala puede prestar a la comunidad, siempre con el buen hacer del animador, serían los siguientes:

a) Las posibilidades de Internet e Intranet: correo electrónico, chat, faq -preguntas y respuestas-, grupos de discusión. Sin olvidar los SMS y MMS que pueden ayudar a crear "familia" (fechas de cumpleaños, recordatorios en tiempos litúrgicos fuertes, y en domingos y fiestas...)

b) Grabación y proyección de documentales, en Vídeos y DVDs...

c) Celebraciones con niños, adolescentes y jóvenes...

d) Conferencias y debates 23 .

En este tema de los ministerios, y antes de subrayar algunas palabras finales, quisiera recordar tres frases agudas y certeras como dardos:

"Cuando creíamos que teníamos todas las respuestas, de pronto, cambiaron todas las preguntas" (Mario Benedetti)

"Hacer una y otra vez lo mismo esperando respuestas diferentes, es una locura" (Einstein)

"En el Evangelio no se dice tanto cómo deben ser las ovejas (que se las acepta tal y como son), sino cómo deben ser los pastores" (Carmen Pellicer).

Es toda una llamada a saber unir creatividad y fidelidad en una Iglesia toda ella Misterio de Comunión para la Misión.

\section{6.- Palabras finales}

A la hora de cerrar estas líneas nos llega la Exhortación Postsinodal "Sacramentum Caritatis" (22-2-07)24. También tiene que ver con nuestro tema, principalmente (no exclusivamente) en los siguientes números: Asambleas dominicales en ausencia de sacerdote (n. 75); Eucaristía y fieles laicos (n. 79); estructura de la celebración eucarística (nn. 43-51); y papel activo de la familia en el proceso y sacramentos de la iniciación (n. 19). En lo que se refiere a las celebraciones, principalmente de la Liturgia

22 CONFERENCIA EPISCOPAL ITALIANA, comunicación y misión. Directorio sobre las comunicaciones sociales en la misión de la Iglesia, EDICE, Madrid 2005.

23 Cf. R. BERZOSA MARTÍNEZ; Transmitir la fe en un nuevo siglo, DDB, Bilbao 2006; ID., La parroquia en la cibercultra: "Signo" 11 (septiembre-octubre 2006) Pliego Central.

24 BENEDICTO XVI, Exhortación Apostólica Postsinodal Sacramentum Caritatis, Editrice Vaticana, Vaticano 2007. 
de la Palabra, dirigidas por un diácono o por un laico responsable de la comunidad, se recomienda, de forma prudente tres cosas: que se siga el ritual aprobado por la Conferencia Episcopal, que el permiso para repartir la comunión haya sido otorgado expresamente por el Ordinario y que, dichas asambleas, no se confundan con el rol, ni mucho menos anulen, el papel propio del sacerdote. Se recomienda, finalmente, que se forme en una sana eclesiología y que se ruegue al dueño de la Mies a favor de las vocaciones al ministerio sacerdotal. En cualquier caso, pide los sacerdotes que no dejen mucho tiempo a las comunidades sin la celebración eucarística. Por lo demás, se recuerda, en el resto de los epígrafes señalados, que la Eucaristía se continúa en la vida, que los laicos están llamados a participar activamente en las celebraciones (siempre desde su rol y condición), y que la familia adquiere un papel imprescindible como mistagoga y acompañante de la fe para las generaciones más jóvenes.

Para concluir nos preguntamos si, más allá de los planteamientos teológicos y doctrinales, el tema de los ministerios ha cuajado, y cómo, en la "praxis ordinaria" de nuestras Iglesias. Para responder a ello nos llega un Directorio de la Diócesis de Osma-Soria' ${ }^{25}$, que puede ser ejemplo significativo de cómo está la situación en general. En dicho Directorio se recuerda qué es un ministerio laical y cómo existen variedad de ministerios, servicios y funciones. $\mathrm{Y}$, dentro de los ministerios, se diferencian los ministerios instituidos, los ministerios reconocidos (con dos niveles: servicios espontáneos y con un reconocimiento sólo de hecho) y los ministerios extraordinarios. Se deben promocionar los ministerios, servicios y funciones de los laicos (pp. 3-9).

Cuando se trata de concretar los ministerios, se establecen los siguientes: entre los ministerios instituidos, los de lector y acólito. Entre los ministros extraordinarios, el de la comunión. Y, en otro orden, el de los ministros de las celebraciones dominicales en espera de presbítero, el de catequista estable, y el de ministerio de la caridad (pp. 10-25). Para promover los ministerios laicales, se han de dar los siguientes pasos: convocatoria y discernimiento, formación, rito para conferir la misión, y evaluación (pp. 26-27).

25 DIÓCESIS DE OSMA-SORIA, Directorio de los ministerios laicales en la Diócesis de Osma-Soria, Separata del Boletín Oficial del Obispado (Julio-Agosto 2006). Se pueden ver otros Directorios como por ejemplo: DIÓCESIS DE VALLADOLID, Ministerios laicales en la Diócesis de Valladolid, Valladolid 2001. 
Tras la lectura de éste como de otros Directorios, hay que concluir que se ha avanzado sin duda en el tema de los ministerios laicales. Tal vez más obligados por la nueva realidad pastoral cambiante que por planteamientos teóricos. La norma seguirá siendo en el futuro la señalada por el Vaticano II en sus documentos: creatividad en la fidelidad. Sin olvidar unas proféticas palabras del cardenal J. Ratzinger, hoy Benedicto XVI en un contexto análogo al que hemos venido tratando: "Participad en la edificación del único cuerpo. Los pastores estarán atentos a no apagar el Espiritu (1 Tes 5,19) y vosotros aportaréis vuestros dones a la comunidad entera. Una vez más: el Espíritu sopla donde quiere, pero su voluntad es la unidad. Él nos conduce a Cristo, a su Cuerpo... El Espiritu Santo quiere la unidad, quiere la totalidad. Por eso, su presencia se demuestra finalmente también en el impulso misionero 26 ". Estas palabras del Papa pueden servir para poner broche de oro al cometido del presente escrito.

\section{LOS MINISTERIOS, ESPECIALMENTE LAICALES, EN UNA IGLESIA "MISTERIO DE COMUNION PARA LA MISION".}

1.- Ministerios, carismas y funciones en una Iglesia "misterio de comunión para la misión".

2.- Profundizando en el tema de los ministerios desde la sana Tradición eclesial

\section{Los ministerios laicales en el nuevo Código de Derecho Canónico:}

En el munus docendi se especifican: el anuncio del evangelio con la palabra y el ejemplo (c. 759,1); la catequesis en general (c. 225; 774; 776; 785; 528; ), la catequesis matrimonial (c. 1063) y familiar (c. 774,2; 851); la evangelización como misionero (c. 784).

26 J. RATZINGER; Los movimientos en la Iglesia. Nuevos soplos del Espíritu, San Pablo, Madrid 2006, 148-149. 
En el munus santificandi se concretan: la participación en los sacramentos (835-899) y en los ministerios litúrgicos dentro y fuera de la Eucaristía (c. 230). Así, ministerio extraordinario de la Palabra; acolitado y lectorado estables o temporales; ministerio extraordinario del Bautismo (861), de la comunión (c. 910), de la exposición del Santísimo (c. 943) y de la celebración de ciertos sacramentales (c. 1168).

En el munus regendi se expresan: las funciones de carácter consultivo (nombramiento de obispos y párrocos) (cc. 377,3; 524); participación en concilios particulares y sínodos diocesanos (cc. 443; 463) y en los consejos pastorales (diocesanos y parroquiales) (cc. 512, 519, 536). Funciones de dirigentes o técnicos: moderador en asociaciones laicas públicas (c. 317,3); administración de bienes eclesiásticos (c. 956; c. 1282); oficios en los tribunales: asesor (c. 1424), auditor (c.1428), promotor de justicia y defensor del vínculo (c. 1435), notario (c. 1436, c. 438), procurador y abogado (c. 1482), perito (c. 1574), ayudante en los interrogatorios (c. 1528 y c. 1717), peritos en los procesos administrativos (c. 1718), mediador (c. 1733), encargado de encontrar solución en las controversias administrativas (c. 1733); delegado y observador de la Santa Sede en Congresos Internacionales (c. 363).

Se señalan además algunos Oficios especiales: predicar en una iglesia u oratorio (c. 766); juez eclesiástico (c. 1421 y c. 1426); superior general de los Institutos de Vida Consagrada y de Sociedades de Vida Apostólica laical. En estos tres oficios especiales colaboran en el ejercicio de la Palabra o del poder de jurisdicción jeráquico. Colaborar no significa participar en la naturaleza de un poder $\mathrm{u}$ oficio, como es el caso de los ministros ordenados.

\section{4.- A vueltas con la Instrucción Vaticana del año 1997}

\section{5.- Últimas aportaciones sobre el tema de los ministerios laicales (desde 2001 hasta hoy).}

\section{6.- Palabras finales}

Bibliografía de Mons. Raúl Berzosa sobre el tema: Ser laico en la Iglesia y en el mundo (DDB); Transmitir la fe en un nuevo siglo (DDB); Diccionario de Pastoral y evangelización (Monte Carmelo) 